\title{
Cultura e espaço na Teoria da Literatura
}

Luis Alberto Brandão

Universidade Federal de Minas Gerais

\begin{abstract}
RESUMO: EXPÕE-SE UMA SUCINTA REFLEXÃO SOBRE A AMBIVALÊNCIA QUE OS TERMOS CULTURA E ESPAÇO APRESENTAM NO PERCURSO HISTÓRICO DA TEORIA DA LITERATURA. PARA TANTO, A REFERIDA AMBIVALÊNCIA É ASSOCIADA À POLARIZAÇÃO, SIGNIFFCATIVAMENTE DETECTÁVEL NAS CORRENTES DE MAIOR REPERCUSSÃO CRÍTICA DO SÉCULO XX, ENTRE A PERSPECTIVA FORMALISTA OU IMANENTISTA E A PERSPECTIVA SOCIOLÓGICA OU CULTURALISTA. INDICAM-SE, AINDA, ALGUMAS TENTATIVAS, EM ÂMBITO TEÓRICO, DE SE EQUACIONAR TAL POLARIZAÇÃO.

RESUMEN: SE EXPONE UNA SUSCINTA REFLEXIÓN SOBRE LA AMBIVALENCIA QUE PRESENTAN LOS TÉRMINOS CUITURA Y ESPACIO EN EL PRECURSO HISTÓRICO DE LA TEORÍA DE LA LITERATURA. PARA ELLO, LA REFERIDA AMBIVALENCIA SE ASOCIA A LA POLARIZACIÓN, PARTICULARMENTE PERCEPTIBLE EN LAS CORRIENTES DE MAYOR REPERCUSIÓN CRÍTICA DEL SIGLO XX, ENTRE LA PERSPECTIVA FORMALISTA O IMANENTISTA Y LA PERSPECTIVA SOCIOLÓGICA O CULTURALISTA. SE INDICAN, AÚN, ALGUNOS INTENTOS, EN ÁMBITOS TEÓRICOS, DE SOLUCIONAR TAL POLARIZACIÓN.
\end{abstract}

PALAVRAS-CHAVE:TEORIA DA LITERATURA, ESPAÇO, CULTURA, AMBIVALÊNCIA, REALIDADE. PALABRAS-CLAVE: TEORÍA DE LA LITERATURA, ESPACIO, CULTURA, AMBIVALENCIA, REALIDAD. 
ultura e espaço são termos de difícil definição. Podem traduzir noções de grande abrangência, que englobam muitas outras noções. Também podem representar categorias estritas, que designam atividades ou fenômenos específicos. São utilizados em várias áreas de conhecimento, mais ou menos formalizadas em disciplinas com metodologia e corpo teórico próprios. Além disso, estão incorporados ao uso corrente das línguas ocidentais, constituindo referências importantes no discurso quotidiano. Ambos os termos, seja nos circuitos especializados, seja nas esferas informais, apresentam, temporalmente, expressivas variações, ou seja, seu significado transforma-se historicamente, ainda que recorrências também se verifiquem.

Apesar da dificuldade de se circunscrever a diversidade de concepções vinculáveis a ambos, cultura e espaço podem ser pensados, conjuntamente, a partir de duas perspectivas elementares. Segundo a primeira perspectiva, os termos designam algo que possui, em si, uma realidade, descrevem circunstâncias ou eventos concretos. Há, pois, uma qualidade empírica naquilo a que se referem. Conforme a segunda vertente, designam abstrações, mesmo que estas se ancorem em dados palpáveis. Referem-se a sistemas de convenções, valores, formas de atribuição de sentido. Ganha destaque a natureza conceitual da operação designativa que efetuam.

Assim, para se abordar o termo espaço, é preciso levar em conta, por um lado, as diferentes manifestações do que se entende por percepsão espacial, as quais incluem tanto os sentidos do corpo humano quanto os sistemas tecnológicos, rudimentares ou complexos, de observação, mensuração e representação da realidade física. Por outro lado, deve-se considerar o espaço como conceito, construto mental utilizado na produção do conhecimento humano, seja de natureza científica, filosófica ou artística.

Quanto a cultura, é necessário admitir a importância de sua fundamentação empírica, já que o termo compreende o conjunto de atividades e determinações de um certo modo de viver, a configuração objetiva de uma ordem social. Por outro lado, exprime um sistema amplo, e em muitos casos difuso, de significações, a articulação tácita, nem sempre demonstrável, de valores. É a essa segunda perspectiva que dá relevo Max Weber, que, para defender que a Ciência Social é uma "ciência da realidade", ${ }^{1}$ refere-se a cultura da seguinte maneira:

\footnotetext{
${ }^{1}$ WEBER, Max. "A “objetividade" do conhecimento nas Ciências Sociais". COHN, Gabriel (org.). Weber. 5. ed., São Paulo: Ática, 1991. Coleção Grandes Cientistas Sociais, vol. 13. p. 88
} 
O conceito de cultura é um conceito de valor. A realidade empírica é 'cultura' para nós porque e na medida em que a relacionamos a idéias de valor. Ela abrange aqueles e somente aqueles componentes da realidade que através desta relação tornam-se significativos para nós. ${ }^{2}$

A relação entre as duas perspectivas pode ser dar de muitos modos. $\mathrm{O}$ mínimo que se é levado a consentir é que, em determinado contexto de uso dos termos cultura e espaço, dificilmente elas surgem isoladas. Coexistindo, ainda que conforme diferentes arranjos, tais perspectivas atuam como vetores de força variável que inexoravelmente agregam, aos termos, algum grau de ambivalência. Pode-se afirmar, pois, que cultura e espaço são termos em cujo cerne se detecta a oscilação entre o ato de referir-se a dados e o de gerar construtos, entre a vocação empirista e a tendência idealista.

Cabe indagar, então, qual o papel representado pelos dois termos no percurso histórico da Teoria da Literatura, compreendida na acepção moderna de campo conceitual e metodológico voltado para o objeto literário. Como esboço de resposta, propõe-se, aqui, um breve paralelo entre a ambivalência de tais termos e a significativa polarização detectável nas correntes de maior repercussão crítica da Teoria da Literatura. O século XX deixou como herança o embate que contrapõe o prisma formalista ou imanentista - cuja premissa básica é haver uma especificidade no modo como a linguagem literária se configura, premissa verificável, com as devidas variantes, no Formalismo Russo, no New Criticism, na Estilística, no Estruturalismo e no Pós-Estruturalismo - ao prisma sociológico ou culturalista - o qual se esforça para entender a literatura em seu vínculo, mais ou menos determinista, com fatores históricos e sociais, como ocorre na Sociologia da Literatura e nos Estudos Culturais. Pode-se mesmo reconhecer, nessa polarização, a luta entre o legado romântico-idealista, que advoga a autonomia da obra de arte, cuja negatividade se manifesta especialmente no universo das formas, e o legado realista-positivista, que concebe a obra como reflexo do mundo, sobretudo por meio dos conteúdos sociais que é capaz de veicular.

\footnotetext{
2 WEBER, Max. "A “objetividade" do conhecimento nas Ciências Sociais". COHN, Gabriel (org.). Weber. 5. ed., São Paulo: Ática, 1991. Coleção Grandes Cientistas Sociais, vol. 13. p. 92.
} 
A consolidação da Teoria da Literatura se inicia, nos primórdios do século XX, mediante a busca pela especificidade de seu objeto - a busca pela literaturnost, ou literaturidade -, o que pressupunha o distanciamento da Estética (como ramo da Filosofia), a recusa das análises de cunho impressionista ou de decodificação simbólico-metafísica, e o questionamento de abordagens cuja ênfase recaía em aspectos "extrínsecos" ao texto, de natureza historicista, psicológica, biográfica ou sociológica. A perspectiva imanentista esteve associada não apenas à difusão da Lingüística, mas à grande força do pensamento de vanguarda, ou, se se prefere, do projeto artístico modernista, na primeira metade do século XX.

Essa associação torna tentadora a hipótese de que os termos cultura e espaço não ocupam posição de destaque nas teorizações das correntes que adotam tal perspectiva pelo fato de que, em linhas gerais, as vanguardas se recusam a atribuir à arte o papel de representação da realidade. Assim, se cultura e espaço eram vistos como categorias empíricas derivadas da percepção direta do mundo, conforme sobretudo a tradição realista-naturalista, vinculada à linhagem positivista do século XIX, estas não despertam especial interesse teórico em um pensamento que, essencialmente antimimético, já que concebe a mimese como imitatio, coloca no centro a própria linguagem. Luiz Costa Lima, no artigo significativamente intitulado "Um conceito proscrito: mimese e pensamento de vanguarda", afirma:

a linguagem se converteu no centro a explorar e sua conquista se media por sua ductibilidade quanto ao que ignoram, desprezam ou temem os servidores, voluntários ou involuntários, da sociedade estabelecida. Como uma bola de neve, este processo cresce desde os românticos até o aparecimento das vanguardas, nas primeiras décadas do século XX. ${ }^{3}$

Não se pode esquecer, naturalmente, do movimento contrário que ocorre no âmago ou nas imediações das vertentes formalistas, como no debate, ainda que não plenamente desenvolvido por razões políticas, sobre a

\footnotetext{
${ }^{3}$ COSTA LIMA, Luiz. "Um conceito proscrito: mimese e pensamento de vanguarda". Sociedade e discurso ficcional. Rio de Janeiro: Guanabara, 1986. p. 320.
} 
historicidade e a evolução das formas literárias, empreendido por Tynianov (1971) e, de maneira mais sistemática, na obra de Mikhail Bakhtin, o qual, inspirado na teoria da relatividade, formula o conceito de "cronotopo" para evidenciar não somente a "indissolubilidade de espaço e de tempo", mas também a concretude histórica de tais termos, e para operar com uma "categoria conteudístico-formal da literatura”. "Também é inegável que Bakhtin propõe uma mirada na qual cultura e espaço se vinculam intimamente, ainda que não fique claro em que medida tal vinculação é metafórica:

Não se deve, porém, imaginar o domínio da cultura como uma entidade espacial qualquer, que possui limites, mas que possui também um território interior. Não há território interior no domínio cultural: ele está inteiramente situado sobre fronteiras, fronteiras que passam por todo lugar, através de cada momento seu, e a unidade sistemática da cultura se estende aos átomos da vida cultural, como o sol se reflete em cada gota. ${ }^{5}$

O Estruturalismo, que se difunde a partir dos anos 1960, tendo na França seu foco irradiador, surge como espécie de retomada e revisão dos pressupostos formalistas. Em sua qualidade de elo com tal tradição, sobretudo em função do mesmo vínculo com a Lingüística, preserva a ênfase na "gramaticalidade" do texto literário, o que significa que, na teoria da narrativa, as categorias cultura e espaço, entendidas como referências a um possível mundo extratextual reconhecível, continuam a desempenhar papel secundário. Os focos de interesse são as vozes, as temporalidades e as ações. Para Roland Barthes, por exemplo, em "Introdução à análise estrutural da narrativa", os dados espaciais são classificados como "informantes", cuja função discursiva é atuar como "operador realista", tarefa acessória em relação às "funções" (divididas em núcleos e catálises) que determinam as "articulações da narrativa". 6

É por intermédio do pensamento estruturalista, porém, que ganha força a idéia de que, com o privilégio da sincronia sobre a diacronia, as questões

\footnotetext{
${ }^{4}$ BAKHTIN, Mikhail. Questões de literatura e de estética. São Paulo: Unesp, Hucitec, 1988. p. 211.

${ }^{5}$ Id Ibid. p. 29.

${ }^{6}$ BARTHES, Roland et al. Análise estrutural da narrativa. 2. ed., Petrópolis: Vozes, 1972. p. 28-35.
} 
relativas a gênese ou filiação, ou seja, vinculadas a um "determinismo temporal", dão lugar à investigação das relações que definem a coerência interna das sociedades, das culturas e das obras, isto é, nas palavras de Gérard Genette, a um "determinismo espacial". 7 Não se pode esquecer, além disso, que a principal propulsão ao debate estruturalista veio da Antropologia Estrutural desenvolvida por Claude Lévi-Strauss. A partir desse debate, cultura e espaço passam a ser tratados não apenas como categorias da realidade identificáveis em obras, para efeito de uma análise literária -, mas também como processo interpretativo, modelo de leitura, sistema de linguagem. Simultaneamente a essa ampliação, que acena com a promessa de uma Semiologia Geral, e coerentemente com a tendência não-mimética baseada na concepção autotélica de linguagem, passa-se a falar, de maneira bastante genérica, e usualmente metafórica, em "linguagem da cultura" e "espaço da linguagem". Genette conclui seu artigo "Espaço e linguagem” afirmando:

Hoje a literatura - o pensamento - exprime-se apenas em termos de distância, de horizonte, de universo, de paisagem, de lugar, de sítio, de caminhos e de morada: figuras ingênuas, mas características, figuras por excelência, onde a linguagem se espacializa a fim de que o espaço, nela, transformado em linguagem, fale-se e escreva-se. ${ }^{8}$

O artigo de Genette é uma análise do livro L'espace humain, em que Georges Matoré caracteriza o "espaço literário" precisamente em função das dimensões sensoriais que a linguagem pode explorar: "la conception de l'espace est une sorte de synthèse opérée en partant de différentes sensations."

Pode-se supor que, para conjugar o marcante antiempirismo - que oblitera o interesse pelas categorias cultura e espaço segundo um prisma mimético - à obsessão sincrônica - que abre caminho ao fascínio por uma noção genérica de espacialização e toma o mundo cultural como sistema de linguagem -, o Estruturalismo extrai da realidade apenas o elemento sensível - justamente o

\footnotetext{
${ }^{7}$ GENETTE, Gérard. "Estruturalismo e crítica literária”. COELHO, Eduardo Prado (org.). Estruturalismo - antologia de textos teóricos. Lisboa: Portugália, 1968. p. 379.

${ }^{8}$ GENETTE, Gérard. Figuras. São Paulo: Perspectiva, 1972. p. 106.

${ }^{9}$ MATORÉ, Georges. L'espace humain. Paris: La Colombe, 1962. p. 213.
} 
que se manifesta por meio das formas -, aplicando-o como dado essencial na definição da linguagem literária. Pode-se, pois, trabalhar com a hipótese de que, para o Estruturalismo, cultura e espaço constituem veículos para se estabelecer um "empirismo da linguagem".

Cabe indagar, então, quais são os desdobramentos da presença dos termos cultura e espaço posteriormente ao momento estruturalista. Em uma breve panorâmica, pode-se verificar que o denominado Pós-Estruturalismo, ou Desconstrucionismo, em geral representa a explicitação e a intensificação da tendência espacializante. Recusando as pretensões científicas do Estruturalismo, investe-se sobretudo contra a lógica que opera por pares opositivos, buscando-se realizar a crítica ao logocentrismo, ou seja, à ordem do logos, do sentido tomado como verdade. Deve-se ressaltar, contudo, que a Desconstrução - a que são associadas, não sem controvérsias, obras como, entre outras, as de Gilles Deleuze, Michel Foucault, Jacques Lacan, Paul de Mann e o último Roland Barthes, mas cujo eixo indubitável é a obra de Jacques Derrida - não é uma teoria. Conforme Jonathan Culler, "a desconstrução tem sido variadamente apresentada como uma posição filosófica, uma estratégia política ou intelectual e um modo de leitura". ${ }^{10}$ Não sendo uma teoria, muito menos uma teoria da literatura, não se encontram aí categorias, mas uma discussão sobre possibilidades críticas de abarcá-las. Assim, não há contribuições específicas a se "aplicar" em determinado campo, mas a se inferir de suas propostas. Na questão que concerne a cultura e espaço, tal contribuição pode ser nitidamente verificada pelo menos em dois aspectos. O primeiro diz respeito à negação do sistema de oposições que inclui sentido/forma, alma/corpo, inteligível/sensível, transcendente/empírico, sistema no qual a categoria espaço tendencialmente é inserida no segundo termo. Derrida enfatiza que, em oposições como essas, há um sentido de anterioridade que trata o primeiro termo como essencial, originário, e o segundo como acidental, derivado, o que revela o gesto "metafísico":

o projeto de remontar 'estrategicamente', idealmente, a uma origem ou a uma 'prioridade' simples, intacta, normal, pura, própria, para pensar em seguida a derivação, a complicação, a degradação, o acidente etc. Todos os metafísicos proce-

\footnotetext{
${ }^{10}$ CULLER, Jonathan. Sobre a desconstrução. Rio de Janeiro: Record/Rosa dos Tempos, 1997. p. 99.
} 
deram assim, de Platão a Rousseau, de Descartes a Husserl: o bem antes do mal, o positivo antes do negativo, o puro antes do impuro, o simples antes do complicado, o essencial antes do acidental, o imitado antes do imitador etc. Esse não é um gesto metafísico dentre outros, é a exigência metafísica mais contínua, mais profunda e mais poderosa. ${ }^{11}$

Segundo Terry Eagleton, é considerado metafísico "qualquer sistema de pensamento que dependa de uma base inatacável, de um princípio primeiro de fundamentos inquestionáveis, sobre o qual se pode construir toda uma hierarquia de significações". ${ }^{22}$ A crítica desconstrucionista, colocando sob suspeita as hierarquias, incide precisamente sobre tais sistemas de pensamento. De acordo com essa crítica, deve-se problematizar o entendimento do espaço, e do que se toma por "natural" na esfera da cultura, como categorias "menores", sem poder de transcendência, excessivamente empíricas, tributárias da platitude do universo sensível, facilmente domesticáveis pela razão.

Simultaneamente, porém, num duplo movimento, deve-se recusar a pressuposição de que o espaço possa ocupar o primeiro termo de pares que opõem natureza e cultura, realidade e percepção, fato e interpretação. O espaço não é um "fato natural", ou melhor, se há algo de "natural", ressalte-se que a "natureza" não possui estatuto de presença absoluta. Para Derrida, em seu debate com a obra de Rousseau, "o conceito de natureza e todo o sistema que ele comanda não podem ser pensados a não ser sob a categoria irredutível do suplemento (...), o que supõe que a natureza possa, às vezes, faltar a si mesma, ou, o que não é diferente, exceder a si mesma". ${ }^{13}$ A lógica suplementar é aquela em que a "positividade de uma presença" é corroída:

acrescentando-se ou substituindo-se, o suplemento é exterior, fora da positividade à qual se junta, estranho ao que, para ser por ele substituído, deve ser distinto dele. Diferentemente do complemento, afirmam os dicionários, o suplemento é uma adição exterior. ${ }^{14}$

\footnotetext{
${ }^{11}$ DERRIDA, Jacques. Limited Inc. Campinas: Papirus, 1991. p.130.

${ }^{12}$ EAGLETON, Terry. Teoria da literatura: uma introdução. 3. ed., São Paulo: Martins Fontes, 1997. p. 182

${ }^{13}$ DERRIDA, Jacques. Gramatologia. São Paulo: Perspectiva, 1973. p. 219.

${ }^{14}$ Id. Ibid. p. 178.
} 
Por meio desse duplo movimento, deixa-se de conceber espaço e cultura como entidades positivas, que se definem segundo um empirismo substancialista (de índole desqualificadora de sua dimensão corpórea ou de índole apologética de sua fixidez ontológica), e passa-se a tratá-los como efeito da diferença, ou seja, segundo uma perspectiva radicalmente relacional.

Uma segunda força intelectual que se insurge contra as premissas estruturalistas, em especial contra sua verve imanentista, são os denominados Estudos Culturais, que se organizam inicialmente na Inglaterra dos anos 1960 e 1970, mas são tributários da longa tradição marxista. Por mais surpreendente que possa parecer, os Estudos Culturais não trouxeram, para o debate teórico do século $\mathrm{XX}$, a possibilidade de uma definição mais coesa e precisa do termo cultura. Ainda que esforços de natureza propriamente conceitual tenham sido feitos, como no livro Cultura, de Raymond Williams (2000), não se elucidam ou se exploram as ambivalências do termo, já que os Estudos Culturais não se definem como corrente teórica, e sim como "campo interdisciplinar", "um movimento ou uma rede", o que não exclui sua crescente "codificação acadêmica". ${ }^{15} \mathrm{Na}$ verdade, apresentam-se como crítica à própria noção de teoria; mais especificamente, como defesa de um processo de politização da teoria. Segundo Homi Bhabha:

such negotiations between politics and theory make it impossible to think of the place of the theoretical as a metanarrative claiming a more total form of generality. (...) It is precisely that popular binarism between theory and politics, whose foundational basis is a view of knowledge as totalizing generality and everyday life as experience, subjectivity and false consciousness, that I have tried to erase. ${ }^{16}$

Uma das estratégias principais adotadas para se efetivar a "politização da teoria" é a recusa da especificidade da produção artística - o que, no campo literário, significa contrapor-se frontalmente ao movimento gerador da Teoria da Literatura, baseado na tentativa de fundamentar as peculiaridades de seu objeto, movimento ainda muito marcante no pensamento estruturalista

\footnotetext{
${ }^{15}$ JOHNSON, Richard et al. O que é afinal, Estudos Culturais? Belo Horizonte: Autêntica, 1999. p. 9.

${ }^{16}$ BHABHA, Homi K. The location of culture. London, New York: Routledge, 1990. p. 30.
} 
e a apologia, como campo de ação, de uma ampla, não raro imprecisa, noção de cultura. Conforme reconhece Richard Johnson, "o termo 'cultura' tem valor como um lembrete mas não como uma categoria precisa", ${ }^{17}$ e ainda: "Para mim, boa parte das fortes continuidades da tradição dos Estudos Culturais está contida no termo singular 'cultura', que continua útil não como uma categoria rigorosa, mas como uma espécie de síntese de uma história". ${ }^{18}$

Para os Estudos Literários, a conseqüência mais imediata da abordagem culturalista está na retomada da noção de literatura como representação, ou seja, de uma revalorização da perspectiva mimética. A literatura, que deixa de ter qualquer privilégio em relação à totalidade dos discursos em operação na sociedade, interessa à medida que se oferece como palco onde os vetores conflituosos de determinada configuração cultural se manifestam. Para uma teoria do espaço, tal premissa parece, a princípio, significar uma abertura. De fato, o caráter agonístico das relações culturais coloca em foco os lugares nos quais os discursos são produzidos, o que explica, na difusão do "discurso culturalista", a recorrência de termos como margem, fronteira, entre-lugar, metrópole, colônia, centro, periferia, ocidente, oriente. A "politização", ou a "culturalização", porém, se confundida com mero pragmatismo de interesses imediatistas, por mais nobres que pareçam, corre o risco de levar a uma visão mecânica do que é o processo mimético no discurso literário, e restaurar a concepção de jogo especular arte/sociedade, reveladora de uma visão determinista de história, e da eleição de um projeto de arte em que a afirmatividade se ergue em detrimento de um poder radical de negatividade, ou, dito de outra maneira, em que a negatividade é "domesticada", tomada como instrumental por ideais afirmativos.

A "politização-culturalização" da noção de teoria pode significar, entretanto, que também a noção de espaço se politiza, se "culturaliza". Isso se dá quando se concebe o espaço segundo o prisma de suas definições identitárias, o que corresponde a deslocar a visão empirista de espaço, sem contudo negála. Mediante o enfoque nas identidades, que se definem na interação entre as subjetividades individuais e as referências coletivas, o tratamento do espaço

${ }^{17}$ JOHNSON, Richard et al. O que é afinal, Estudos Culturais? Belo Horizonte: Autêntica, 1999. p. 9.

${ }^{18}$ Id Ibid. p. 20 
não prevê que se dissocie, de sua materialidade, uma dimensão intensamente simbólica. Stuart Hall afirma: "Todas as identidades estão localizadas no espaço e no tempo simbólicos". ${ }^{19}$

Naturalmente, o "espaço da identidade" é marcado não apenas por convergência de interesses, comunhão de valores e ações conjugadas, mas também divergência, isolamento, conflito e embate. Se, como o espaço, toda identidade é relacional, pois só se define na interface com a alteridade, é intrinsecamente político seu principal predicado. "Espaço de identificações" pode ser entendido, genericamente, como sinônimo de cultura. Com efeito, Edward Said abarca, com o termo cultura, a variabilidade de conotações atribuíveis ao espaço, variabilidade que demonstra a centralidade do espaço para a própria definição de cultura:

O sentido geográfico faz projeções - imaginárias, cartográficas, militares, econômicas, históricas ou, em sentido geral, culturais. Isso também possibilita a construção de vários tipos de conhecimento, todos eles, de uma ou outra maneira, dependentes da percepção acerca do caráter e destino de uma determinada geografia. ${ }^{20}$

Se, no início do século XXI, continua-se divorciando as abordagens que privilegiam o que há de peculiar na literatura como sistema de linguagem daquelas que pretendem compreendê-la em seu liame, determinista ou não, com fatores sócio-culturais, é preciso destacar o esforço de uma corrente que procurou, por uma via inusitada, equacionar tal polarização. A proposta de um novo caminho teórico, centrado na recepção das obras, teve como principal mote a constatação, formulada por Hans Robert Jauss, de que "da orientação definida pela escola positivista e pela idealista destacaram-se a sociologia da literatura e o método imanentista, aprofundando ainda mais o abismo entre poesia e história." 21 Para uma teoria da cultura e do espaço na

${ }^{19}$ HALL, Stuart. A identidade cultural na pós-modernidade. 3. ed., Rio de Janeiro: DP\&A, 1999. p. 71.

${ }^{20}$ SAID, Edward. Cultura e imperialismo. São Paulo: Companhia das Letras, 1995. p. 118.

${ }^{21}$ JAUSS, Hans Robert. A bistória da literatura como provocação à teoria literária. São Paulo: Ática, 1994. p. 14. 
literatura, o pressuposto geral da Estética da Recepção tem desdobramentos estimulantes. Se cultura e espaço, assim como qualquer outro elemento associável a um texto, eram em geral tomados como categorias passivas seja porque tidas como irrelevantes para os movimentos da linguagem, seja porque se acreditava que elas podiam ser imediatamente "transpostas" para o campo textual -, passam, a partir de então, a ser concebidos segundo um processo, simultaneamente social e formal, de "horizontes de expectativas", o qual define a variabilidade histórica dos significados culturais e espaciais.

Wolfgang Iser, explorando os caminhos abertos por Jauss, percebe que uma teoria da recepção conduz, necessariamente, a uma reflexão sobre o imaginário:

A recepção não é primariamente um processo semântico, mas sim o processo de experimentação da configuração do imaginário projetado no texto. Pois na recepção se trata de produzir, na consciência do receptor, o objeto imaginário do texto, a partir de certas indicações estruturais e funcionais. Por este caminho se vem à experiência do texto. (...) A recepção, portanto, está mais próxima da experiência do imaginário do que a interpretação, que pode apenas semantizar o imaginário. ${ }^{22}$

É justamente a noção de imaginário que Iser, no livro O fictício e o imaginário (1996), emprega para romper a divisão tácita entre ficção e realidade, criando a tríade definidora de sua proposta de uma "Antropologia Literária".

Segundo Iser, "como o texto ficcional contém elementos do real sem que se esgote na descrição deste real, então o seu componente fictício não tem o caráter de uma finalidade em si mesma, mas é, enquanto fingido, a preparação de um imaginário". ${ }^{23}$ A conseqüência mais imediata dessa concepção triádica reside no imperativo de se abandonar a pretensão de que seus termos possam ser determinados ontologicamente - pretensão que se manifesta, por exemplo, quando se supõe que o fictício se define pela eliminação dos

\footnotetext{
${ }^{22}$ ISER, Wolfgang. "Problemas da teoria da literatura atual". COSTA LIMA, Luiz. Teoria da literatura em suas fontes. 2. ed., Rio de Janeiro: Francisco Alves, 1983. vol. II. p. 381.

${ }^{23}$ ISER, Wolfgang. O fictício e o imaginário. Rio de Janeiro: UERJ, 1996. p. 13.
} 
atributos da realidade. $\mathrm{Na}$ tríade, importa o cunho relacional dos termos, o qual torna impossível que se estabeleçam fundamentos.

Propõe-se, assim, que se pense a literatura segundo uma perspectiva antropológica ampla, ou seja, como produto humano e simultaneamente definidor do humano. Trata-se, pois, não de adotar a mirada da Antropologia como disciplina constituída (mesmo que não se descartem diálogos com vertentes das antropologias cultural, filosófica, social, estrutural, gerativa, histórica), mas de conceber uma Antropologia Literária, que parte da idéia de que há uma "plasticidade humana" 24 que se manifesta de maneira privilegiada na literatura e nas artes, já que estas são capazes de oferecer uma "auto-interpretação do homem". ${ }^{25}$ Desse modo, deixa de possuir relevância a discussão sobre a ênfase na forma ou no conteúdo, significante ou significado, materialidade ou mimese, já que a literatura é entendida como operação que converte a plasticidade humana em texto. Tal plasticidade abarca a experiência do homem com o que percebe como real, o processo imaginário de conceber as limitações e as potencialidades de tal experiência, e a transformação desse processo em obras, ou seja, a concretização do imaginário por meio da ficção.

São inúmeras as potencialidades sugeridas pelas relações entre real, fictício e imaginário - que são, em grande medida, as relações que definem uma cultura - para se investigar a questão do espaço. Pode-se pensar, em primeiro lugar, que historicamente há distintas conformações de uma realidade espacial, como modo de percepção empírica, associada a métodos de observação e representação do espaço e a modelos de organização geopolítica e econômica. Mas deve-se pensar também na existência de um discurso espacial, conjunto de produtos, com graus variados de formalização - incluindo-se aí, sem dúvida, a própria literatura, mas também os discursos científicos e filosóficos - no qual se concretiza, além de um sistema conceitual e operacional, um quadro de referências simbólicas e um conjunto de valores de natureza cultural a que genericamente se denomina imaginário espacial. Se o espaço, como categoria relacional, não pode fundamentar a si mesmo, é através de suas "ficções" que ele se manifesta, seja para vir a ser tomado por real, seja

${ }^{24}$ ISER, Wolfgang. O fictício e o imaginário. Rio de Janeiro: UERJ, 1996. p. 8.
${ }^{25}$ Id Ibid. p. 10. 
para reconhecer-se como projeção imaginária, ou, ainda, para se explicitar, na auto-exposição de seu caráter fictício, como realidade imaginada.

Se alguma conclusão se pode tirar do sucinto percurso aqui traçado, esta diz respeito à premência de se reconhecer que uma suposta fragilidade epistemológica da Teoria da Literatura se explica menos pela natureza incerta de seu objeto de estudo, ou pela carência de sofisticação metodológica, do que pela insuficiência especulativa do trabalho com os conceitos, possivelmente motivada por uma postura de afirmatividade teórica e/ou política que oblitera a negatividade crítica capaz de estabelecer patamares teóricos de fato transgressivos. Para tal reconhecimento, o primeiro passo é admitir o quão ambivalentes são certos termos, em especial aqueles que, mesmo que pela via da sua ausência ou recusa, são conceitos-chave. O segundo passo é consentir que todo conceito-chave, sobretudo quando tomado sob o prisma dos vetores que conformam sua ambivalência, abriga desafios. No caso de cultura e espaço, o desafio parece estar em se buscar uma forma, provocativa e inusitadamente cultural, no sentido de auto-reflexivamente antropológica, de se abordar a relação entre o que é dado e o que é concebido. O passo seguinte, óbvio mas raro, é aceitar, com a indispensável radicalidade, o desafio que os conceitos lançam.

\section{Referências bibliográficas}

BAKHTIN, Mikhail. Questões de literatura e de estética. São Paulo: Unesp, Hucitec, 1988. BARTHES, Roland et al. Análise estrutural da narrativa. 2. ed., Petrópolis: Vozes, 1972. BHABHA, Homi K. The location of culture. London, New York: Routledge, 1990.

CULLER, Jonathan. Sobre a desconstrução. Rio de Janeiro: Record/Rosa dos Tempos, 1997.

DERRIDA, Jacques. Gramatologia. São Paulo: Perspectiva, 1973.

. Limited Inc. Campinas: Papirus, 1991.

EAGLETON, Terry. Teoria da literatura: uma introdução. 3. ed., São Paulo: Martins Fontes, 1997.

GENETTE, Gérard. "Estruturalismo e crítica literária". COELHO, Eduardo Prado (org.). Estruturalismo - antologia de textos teóricos. Lisboa: Portugália, 1968.

Figuras. São Paulo: Perspectiva, 1972.

HALL, Stuart. A identidade cultural na pós-modernidade. 3. ed., Rio de Janeiro: DP\&A, , 1999. 
ISER, Wolfgang. O fictício e o imaginário. Rio de Janeiro: UERJ, 1996.

. "Problemas da teoria da literatura atual". COSTA LIMA, Luiz. Teoria da literatura em suas fontes. 2. ed., Rio de Janeiro: Francisco Alves, 1983. vol. II.

JAUSS, Hans Robert. A história da literatura como provocação à teoria literária. São Paulo: Ática, 1994.

JOHNSON, Richard et al. O que é afinal, Estudos Culturais? Belo Horizonte: Autêntica, 1999.

COSTA LIMA, Luiz. Sociedade e discurso ficcional. Rio de Janeiro: Guanabara, 1986.

MATORÉ, Georges. L'espace bumain. Paris: La Colombe, 1962.

SAID, Edward. Cultura e imperialismo. São Paulo: Companhia das Letras, 1995.

TYNIANOV, J. "Da evolução literária”. TOLEDO, Dionísio de Oliveira (org.). Teoria da literatura - formalistas russos. Porto Alegre: Globo, 1971.

WEBER, Max. "A “objetividade" do conhecimento nas Ciências Sociais". COHN, Gabriel (org.). Weber. 5. ed., São Paulo: Ática, 1991. Coleção Grandes Cientistas Sociais, vol. 13.

WILLIAMS, Raymond. Cultura. 2. ed., São Paulo: Paz e Terra, 2000. 